\title{
Xenogeneic, Extracorporeal Liver Perfusion in Primates Improves the Ratio of Branched-Chain Amino Acids to Aromatic Amino Acids (Fischer's Ratio)
}

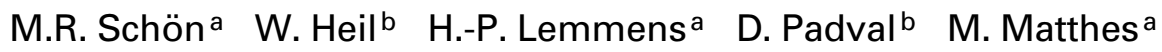 \\ G. Puhla P. Neuhaus ${ }^{a}$ C. Hammer ${ }^{c}$ \\ aDepartment of Surgery, Charité, Campus Virchow-Klinikum, Humboldt-Universität, Berlin, \\ ${ }^{b}$ Central Laboratory, Klinikum Wuppertal, Universität Witten/Herdecke, Wuppertal, and \\ 'Institute of Surgical Research, Klinikum Grosshadern, Ludwig-Maximilians-Universität, \\ München, Germany
}

\author{
Key Words \\ Extracorporeal liver perfusion - Amino \\ acids $\cdot$ Hepatic failure $\cdot$ Hepatic \\ encephalopathy · Primate - Dialysis . \\ Xenogeneic liver perfusion
}

\begin{abstract}
In fulminant hepatic failure (FHF), the development of hepatic encephalopathy is associated with grossly abnormal concentrations of plasma amino acids (PAA). Normalization of the ratio of branched-chain amino acids to aromatic amino acids (Fischer's ratio) correlates with clinical improvement. This study evaluated changes in PAA metabolism during $4 \mathrm{~h}$ of isolated, normothermic extracorporeal liver perfusion using a newly designed system containing human blood and a rhesus monkey liver. Bile and urea production were within the physiological range. Re-
\end{abstract}

\begin{tabular}{|c|c|}
\hline KARGER & $\begin{array}{l}\text { (c) } 1999 \text { S. Karger AG, Basel } \\
0014-312 X / 99 / 0313-0230 \$ 17.50 / 0\end{array}$ \\
\hline $\begin{array}{l}\text { Fax +4161306 } 1234 \\
\text { E-Mail karger@karger.ch } \\
\text { www.karger.com }\end{array}$ & $\begin{array}{l}\text { Accessible online at: } \\
\text { http://BioMedNet.com/karger }\end{array}$ \\
\hline
\end{tabular}

lease of the transaminases AST, ALT and $\mathrm{LDH}$ were minimal. The ratio of branched (valine, leucine, isoleucine) to aromatic (tyrosine, phenylalanine) amino acids increased significantly. These results indicate that a xenogeneic extracorporeal liver perfusion system is capable of significantly increasing Fischer's ratio and may play a role in treating and bridging patients in FHF in the future.

\section{Introduction}

Fulminant hepatic failure (FHF) is regularly associated with encephalopathy [1]. If supportive measures fail, then the stage of encephalopathy progresses and brain edema develops [2]. For many patients, liver transplantation is the therapy of choice that yields the best prognosis for survival and quality of life 
[3-5]. Transplantation must be carried out before irreversible neurologic complications secondary to brain edema occur. Apart from liver transplantation, therapeutic measures such as continuous hemofiltration and plasma exchange have not been very successful in preventing FHF patients from developing brain edema to date [6].

During FHF, grossly abnormal concentrations of a wide variety of plasma amino acids (PAA) can be measured. PAA play a decisive role in the pathophysiology of hepatic encephalopathy (HE) and brain edema [7-9]. Increasing the ratio of branched-chain amino acids (BCAA) to aromatic amino acids (AAA) correlates well with an improvement in HE [10]. Under clinical conditions the source of PAA is difficult to determine. The source can be either the diseased liver or the body muscle mass.

During the late 60 s and early 70 s, extracorporeal liver perfusion with livers from different species was investigated as a method to treat patients in FHF, expecting the affected liver would regenerate $[11,12]$. Recently, the same technical approach of liver perfusion has been applied in FHF patients waiting for liver transplantation [13]. So far, no evidence has been presented that a normothermic extracorporeal liver perfusion (NELP) system is capable of improving the BCAA to AAA ratio.

This study examines the role of an improved NELP system utilized under defined conditions on changes in PAA levels and the BCAA/AAA ratio.

\section{Methods}

Six rhesus monkeys (Macaca mulatta) of either sex weighing $10.3 \pm 0.6 \mathrm{~kg}$ were used as multiple organ donors. All animals received a standard commercial diet and were allowed free access to food and water prior to hepatectomy.

Xenogeneic, Extracorporeal Liver Perfusion Improves Fischer's Ratio
Organ Harvesting. After intramuscular premedication with ketamine hydrochloride, anesthesia was induced with etomidate and azaperone followed by endotracheal intubation. Maintenance of anesthesia was carried out with halothane, fentanyl and a mixture of oxygen and nitrous oxide on a mechanical ventilator. A midline abdominal incision was made from the xiphoid process to pubis. The liver was dissected and the infraand suprahepatic vena cava, portal vein, common bile duct, and hepatic artery were exposed. The common bile duct was ligated and divided as distally as possible. The gallbaldder was excised and the cystic duct ligated. Branches of the celiac and hepatic arteries to the stomach and duodenum were ligated and divided along with the coronary artery and phrenic veins and all connective tissue surrounding the liver. A ligature was placed around the descending thoracic aorta. The kidneys and ureters were manipulated before organ perfusion. A thoracotomy was carried out, and the heart and lungs were prepared for organ removal. For organ perfusion one catheter was placed in the abdominal aorta and a second catheter in the portal vein. The portal vein and the abdominal aorta were perfused with $400 \mathrm{ml}$ University of Wisconsin (UW) solution, respectively. For storage, the liver was wrapped in a double plastic bag and stored at $0^{\circ} \mathrm{C}$ in UW solution. The storage period varied from 60 to $80 \mathrm{~min}$.

Liver Perfusion. At the end of the storage period, livers were prepared for perfusion by inserting spring perfusion cannulae into the portal vein, vena cava and hepatic artery. Then the liver was placed in a plastic bag and immersed in water $\left(37^{\circ} \mathrm{C}\right)$ contained in a specially designed perfusion chamber. The liver was subjected to intermittent oscillations produced by an external pump. The pressure difference was in the range of 0 to $25 \mathrm{~cm} \mathrm{H}_{2} \mathrm{O}$. The liver was perfused via cannulae in the portal vein and hepatic artery. The suprahepatic vena cava was ligated while blood outflow was allowed through the infrahepatic vena cava. According to physiological conditions, the mean arterial pressure was adjusted to $100 \mathrm{~mm} \mathrm{Hg}$ and the portal venous pressure to $15 \mathrm{~cm} \mathrm{H}_{2} \mathrm{O}$. The flow rates measured under these conditions were about $150 \mathrm{ml} / \mathrm{min}$ through the hepatic artery and $250 \mathrm{ml} / \mathrm{min}$ through the portal vein. Our perfusion system allows for easy control and adjustment of flow rates and perfusion pressures. The Dideco D701 pediatric hollow fiber oxygenator was supplied with a mixture of $95 \%$ oxygen and $5 \%$ carbon dioxide. Bile production was measured continuously. Since the livers were stored in UW solution, we flushed them with warm and equilibrated perfusate according to our clinical protocol. The first $200 \mathrm{ml}$ of perfusate were discarded before perfusion was started.

Eur Surg Res 1999;31:230-239 231 
Fig. 1. The liver was placed in a sterile plastic bag, which was then immersed at $37^{\circ} \mathrm{C}$ in water and was subjected to intermittent oscillations produced by an external pump. The liver was perfused via cannulae in the portal vein and hepatic artery. The suprahepatic vena cava was ligated while blood outflow was allowed through the infrahepatic vena cava. The Dideco D701 pediatric hollow-fiber oxygenator was supplied with a mixture of $95 \%$ oxygen and $5 \%$ carbon dioxide. The simultaneous dialysis circuit consisted of two Stöckert roller pumps, a Gambro ALWALL GFS 12 fiber dialyzer and a reservoir containing 10 liters of dialysate.

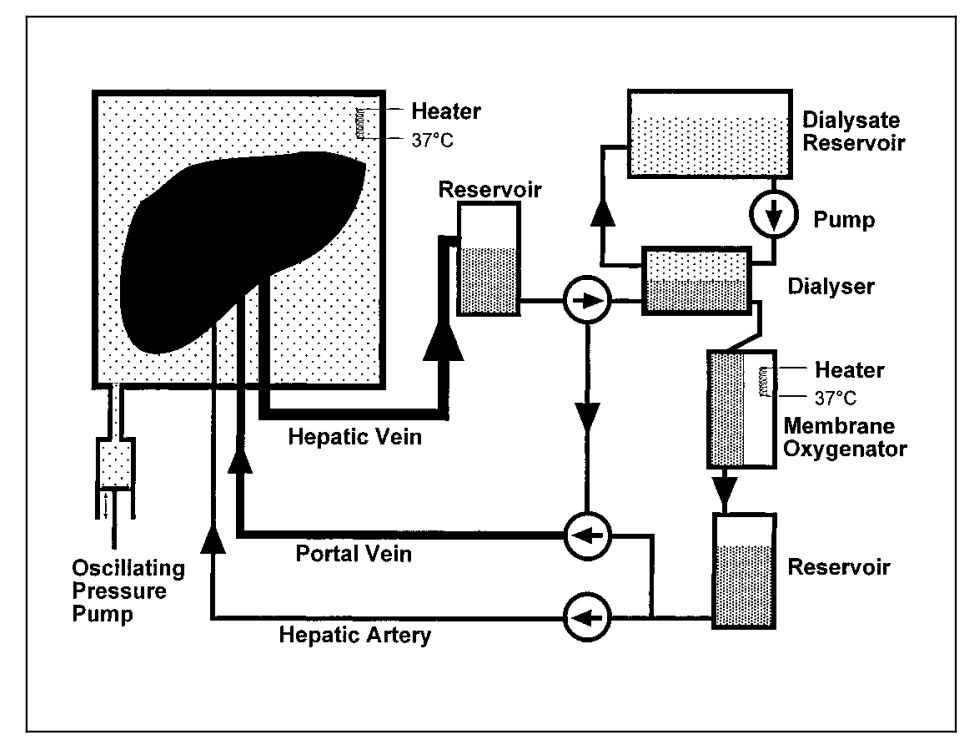

Perfusate. The perfusate consisted of $800 \mathrm{ml} \mathrm{hu-}$ man blood and $400 \mathrm{ml}$ of a balanced electrolyte solution to give a total volume of 1.2 liters. The blood was donated by healthy blood donors 90 min before each perfusion. The monkeys were tested not to have any preformed antibodies for blood groups $\mathrm{O}$ and $\mathrm{B}$. Only blood from donors of blood groups $\mathrm{O}$ and $\mathrm{B}$ was used as perfusate.

Dialysis. The dialysis circuit consisted of a Gambro ALWALL GFS12 fiber dialyzer (Gambro, Lund, Sweden), two Stöckert roller pumps (Stöckert-Shiley, Munich, Germany) and a reservoir for the dialysate. The perfusate was pumped at a steady rate of about $150 \mathrm{ml} /$ min through the dialyzer. The dialysate was pumped at a rate of $1,000 \mathrm{ml} / \mathrm{min}$ from the reservoir and back in a recirculating fashion. Both sides of the dialzyer were controlled and if necessary adjusted to keep the volumes of perfusate/dialysate constant. The perfusate which had passed the dialyzer is pumped back into the main perfusion circuit to be oxygenated. The perfusion-dialysis apparatus including all tubes and the fiber oxygenator were primed with an albumin-containing electrolyte solution to avoid hemolysis. The priming solution was discarded after 10 min of perfusion. Heparin was continuously injected at a rate of $2,500 \mathrm{U} / \mathrm{h}$ to protect the perfusate in the circuit from clotting. Figure 1 shows a diagram of the perfusion circuit.

Dialysate. Ten liters of dialysate were prepared before each experiment. The dialysate consisted of commercially available acid and basic bicarbonate concentrate and distilled water. The dilution ratios were $1: 1.78$ and $1: 42.22$, respectively. The prime buffer of the dialysate was sodium bicarbonate. The electrolyte concentrations of the dialysate (in $\mathrm{mmol} / \mathrm{l}$ ) were $\mathrm{Na}^{+} 141, \mathrm{~K}^{+} 2.9, \mathrm{Ca}^{2+} 0.8, \mathrm{Mg}^{2+} 0.38, \mathrm{Cl}^{-} 113$, $\mathrm{CH}_{3} \mathrm{COO}^{-} 2.5$ and $\mathrm{HCO}_{3}{ }^{-}$37. The osmolality of the dialysate was $296 \mathrm{mosm} / \mathrm{kg}$.

Amino Acids. The samples were deproteinated by adding $50 \mathrm{mg}$ sulfosalicylic acid (Merck) per 1-ml sample, centrifugated at $10,500 \mathrm{~g}$ for $5 \mathrm{~min}$, ultrafiltered through a membrane with a pore size of $0.2 \mu \mathrm{m}$ (Minisart NML, Sartorius), adjusted to a $\mathrm{pH}$ of 2.2, and finally diluted 1:2 with diluent containing norleucine as an internal standard prior to injection. Analyses were performed on a Pharmacia/LKB Alpha Plus amino acid analyzer containing ultrapack cation-exchange resin column (Pharmacia, Uppsala, Sweden) and equipped with a Shimadzu integrator. The post-column ninhydrin reaction was carried out at $135^{\circ} \mathrm{C}$. The system used changes in the eluent lithium citrate buffer from $\mathrm{pH} 2.8 / 0.2 \mathrm{~mol} / 1$ to $\mathrm{pH} 3.55 / 1.65 \mathrm{~mol} / \mathrm{l}$ and a regeneration solution of $0.3 \mathrm{~mol} / \mathrm{l}$ lithium hydroxide. Changes in column temperature were between 32 and $75^{\circ} \mathrm{C}$.

Analyses. Six livers were perfused. Perfusate and dialysate samples were taken before, during (at 15 and $30 \mathrm{~min}$ ) and after perfusion (every $30 \mathrm{~min}$ ). Perfusion was carried out over a period of $4 \mathrm{~h}$. Enzyme activities are given in units per liter per $100 \mathrm{~g}$ liver weight. Electrolyte concentrations are given in millimoles per liter. Amino acid levels are expressed as means \pm SEM (in 
Fig. 2. The activities of AST, ALT, and LDH (U/1/100 g) increased after reperfusion until $15 \mathrm{~min}$. This was atrributed to hepatocellular damage caused by preservation injury. During the following $225 \mathrm{~min}$, the enzyme activity remained fairly constant. Based on the significant increase in urea $(\mathrm{mmol} / \mathrm{l})$ in both perfusate $(1.2 \mathrm{li}-$ ters of circulating volume) and dialysate (10 liters of circulating volume) and a normal production of bile, the system apparently provided physiological conditions for the perfused livers.

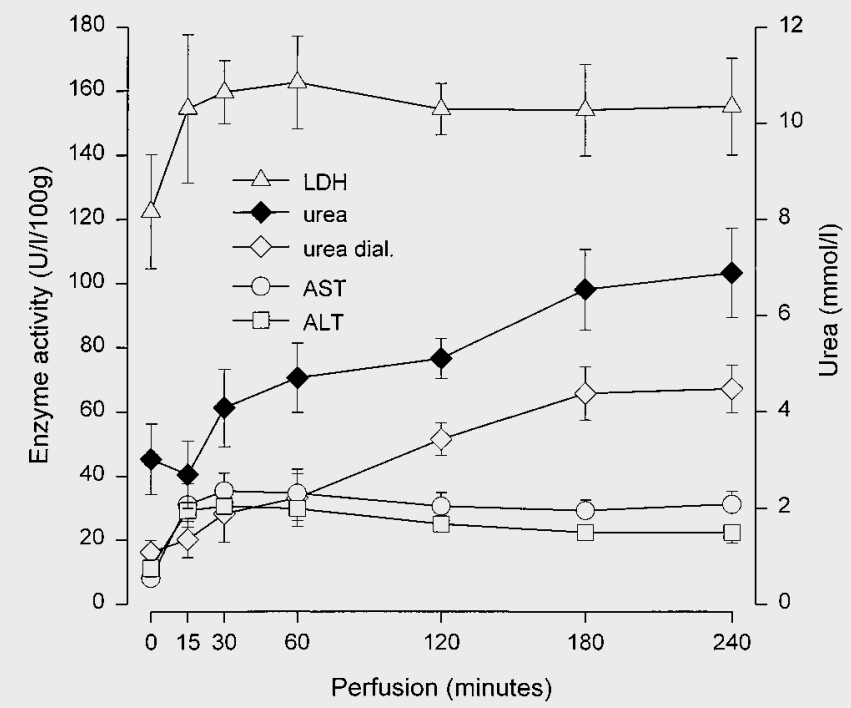

excess electrolyte released after reperfusion. As it has been shown recently [14], the dialysis unit assists in maintaining physiological concentrations of $\mathrm{pH}$ and electrolytes throughout the perfusion period.

During the whole perfusion process, no enzyme activity could be detected in the dialysate. Figure 2 shows the changes in enzyme activity in the perfusate and urea concentrations in perfusate and dialysate during the $4 \mathrm{~h}$ of liver perfusion. The activity of AST in the perfusate before reperfusion was $8 \mathrm{U} / 1 / 100 \mathrm{~g}$. Following $15 \mathrm{~min}$ of perfusion it increased to $25 \mathrm{U} / \mathrm{l} / 100 \mathrm{~g}$. After $240 \mathrm{~min}$ of perfusion the activity measured was $27 \mathrm{U} / 1 / 100 \mathrm{~g}$. ALT increased from $11 \mathrm{U} / 1 / 100 \mathrm{~g}$ before reperfusion to $21 \mathrm{U} / \mathrm{l} / 100 \mathrm{~g} 15 \mathrm{~min}$ thereafter. The activity of ALT for the remaining $225 \mathrm{~min}$ of perfusion was $17-23 \mathrm{U} / 1 / 100 \mathrm{~g}$ and without a clear trend in either direction. LDH activity increased from $123 \mathrm{U} / 1 / 100 \mathrm{~g}$ before reperfusion to $155 \mathrm{U} / 1 / 100 \mathrm{~g}$ after $240 \mathrm{~min}$. Similar to 

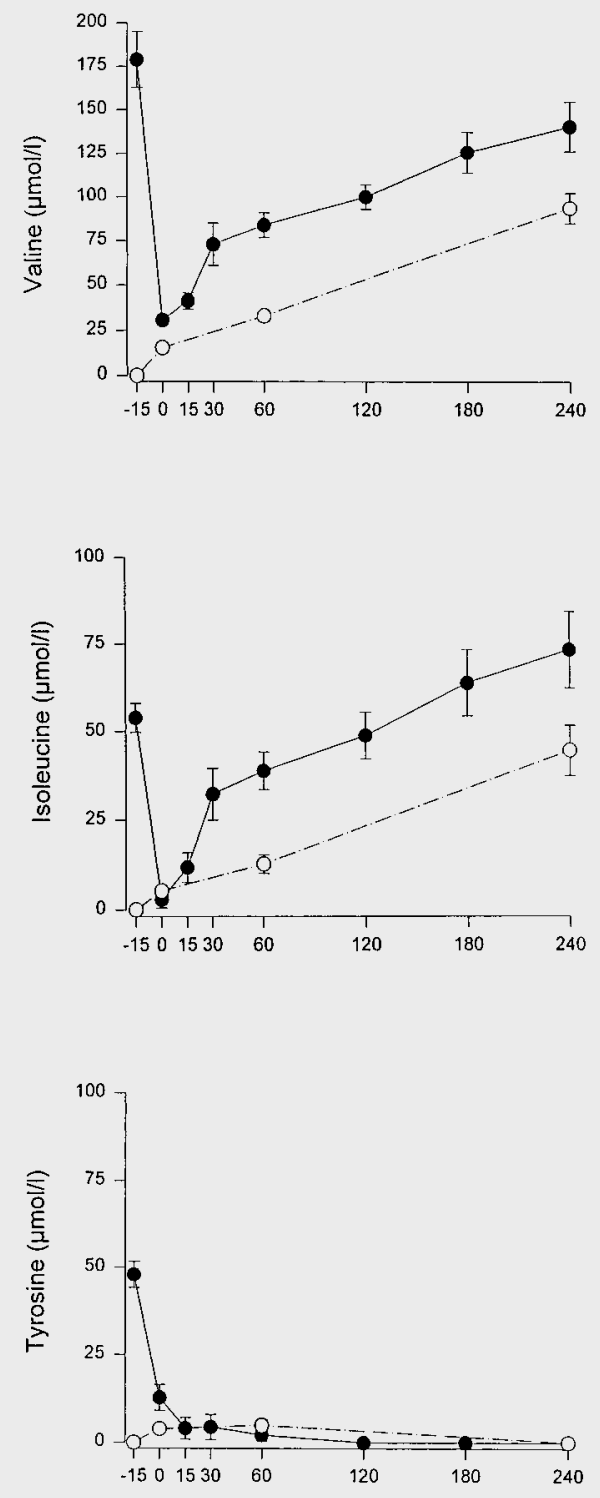

Fig. 3. The BCAA (valine, leucine, and isoleucine) and the AAA concentrations (tyrosine and phenylalanine) are given during $4 \mathrm{~h}$ of liver perfusion. PAA concentrations $(\mu \mathrm{mol} / \mathrm{l})$ of the perfusate (closed symbols) and dialysate (open symbols) are given. The point -15 corresponds to initial levels in the perfusate and dialysate.
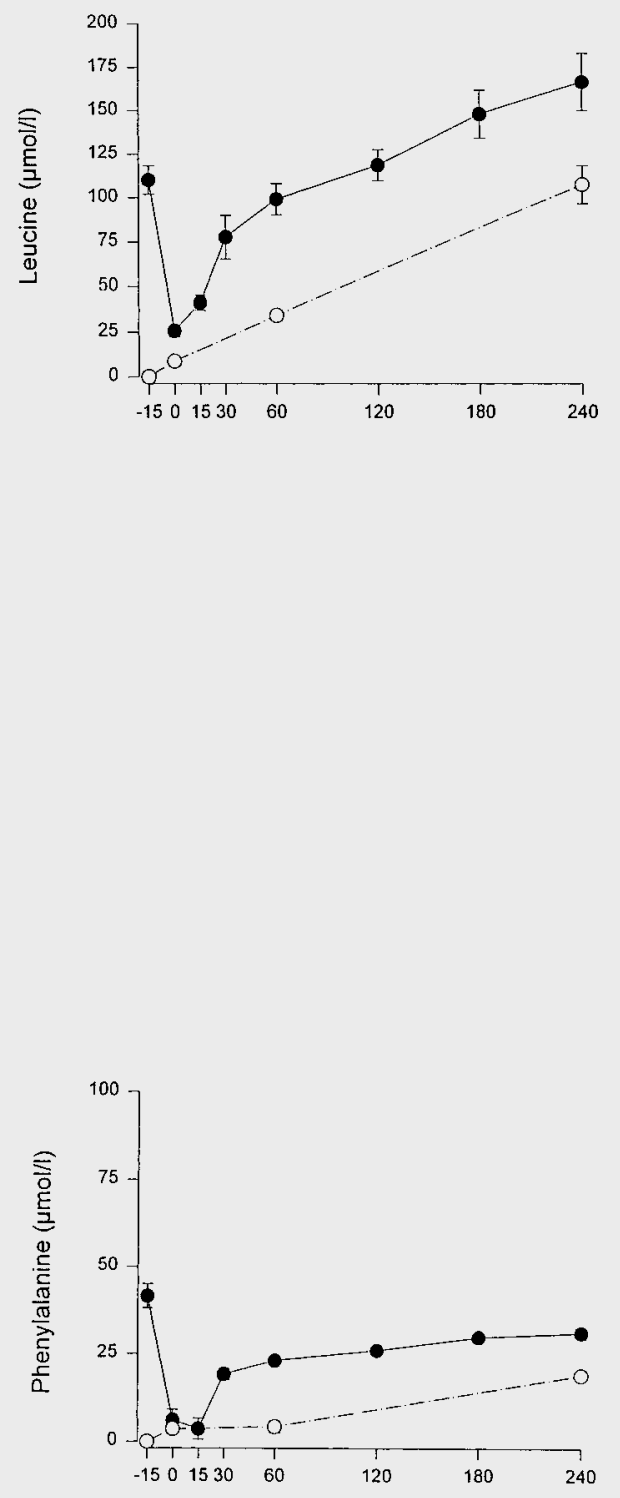

Time point 0 min reflects the concentrations of PAA after an equilibration period of $15 \mathrm{~min}$ between the perfusate (1.2 liters) and the dialysate (10 liters) just prior to liver reperfusion. Positive time points correspond to the period of liver perfusion. Means \pm SEM. 
AST and ALT, the largest increase in LDH release was measured immediately after reperfusion.

During the equilibration period, the concentration of urea in the perfusate was 2.8 $\mathrm{mmol} / \mathrm{l}$. The concentration of urea at the end of perfusion was $6.9 \mathrm{mmol} / \mathrm{l}$ in the perfusate. The amount of urea in the dialysate paralleled the increase in the perfusate. After equilibrium, but before reperfusion, the urea concentration was $1.1 \mathrm{mmol} / \mathrm{l}$. It increased steadily reaching $4.5 \mathrm{mmol} / \mathrm{l}$ at $240 \mathrm{~min}$. Bile production was noted about $20 \mathrm{~min}$ after reperfusion. The average amount of bile produced per $100 \mathrm{~g}$ liver weight was $2.6 \mathrm{ml}$ during the $1 \mathrm{st} \mathrm{h}$ of perfusion, $3.5 \mathrm{ml}$ during the $2 \mathrm{nd} \mathrm{h}$, $3.3 \mathrm{ml}$ during the $3 \mathrm{rd} \mathrm{h}$ and $2.5 \mathrm{ml}$ during the 4th $\mathrm{h}$ of perfusion.

A more detailed description of perfusion parameters has been given recently [15].

\section{Amino Acids}

The concentrations of amino acids in the perfusate and dialysate are given in figures 3 and 4 . Time point -15 min corresponds to the PAA concentration of the perfusate just before starting dialysis. At time point $0 \mathrm{~min}$ the perfusate had been dialysed for $15 \mathrm{~min}$, but reperfusion of the liver had not begun.

The ratios of BCAA/AAA [(valine+leucine+isoleucine $) /($ tyrosine+phenylalanine $)]$ in the perfusate are given in figure 5. At -15 (before dialysis), 0, 60 and $240 \mathrm{~min}$, the ratios were $3.1,3.8,8.8$, and 12.1 , respectively, in the perfusate. Calculation of the ratios for the dialysate gave very similar results. At $0 \mathrm{~min}$, the ratio was 3.6 , at $60 \mathrm{~min}$ the ratio was 8.7 and at $240 \mathrm{~min}$ it was 12.9 . The increased BCAA/AAA ratios between 0 (before liver perfusion) to 60 and $240 \mathrm{~min}$ after liver reperfusion were statistically significant in both the perfusate $(\mathrm{p}<0.01$ and $\mathrm{p}<0.001)$ and dialysate $(\mathrm{p}<0.01$ and $\mathrm{p}<0.001)$.

Xenogeneic, Extracorporeal Liver Perfusion Improves Fischer's Ratio

\section{Discussion}

Approximately 2,000 cases of FHF are diagnosed annually in the United States, with mortality approaching 80\% [16]. Despite improvements in conservative medical treatments, liver transplantation remains the therapy of choice for a large number of patients [17].

In patients with FHF, PAA levels deviate considerably [18]. The BCAA valine, leucine and isoleucine are low - in contrast to most other PAA [19]. There is strong clinical and experimental evidence that elevated PAA levels are a prerequisite for the development of HE and brain edema $[9,10]$. Normalization of PAA has been previously attempted by hemodialysis and plasma exchange [20]. In a group of 26 patients with FHF and signs of grade IV coma, levels of BCAA were lowest in those patients that subsequently died [18]. The adjustment of the molar BCAA/AAA ratio from 1 (e.g. in hepatic coma) towards 3 (normal subjects) has a beneficial effect upon encephalopathy [19]. The BCAA/AAA ratio is increased in patients receiving supplemental BCAA [21]. The role of oral BCAA supplements in the treatment of chronic HE is not yet established, and conflicting opinions have been advanced [22-26]. Two meta-analyses of randomized clinical trials support the view that BCAA are improving hepatic encephalopathy even when given orally $[27,28]$. Although BCAA and AAA play important roles in the development of brain edema, experimental evidence is lacking that an extracorporeally perfused liver can improve this ratio. Liver function in an NELP system is determined by appropriate physiological perfusion conditions.

We have developed a perfusion system in which the liver is immersed in a closed perfusion chamber that allows for intermittent pressure oscillations. This proved to be indis-

Eur Surg Res 1999;31:230-239 235 

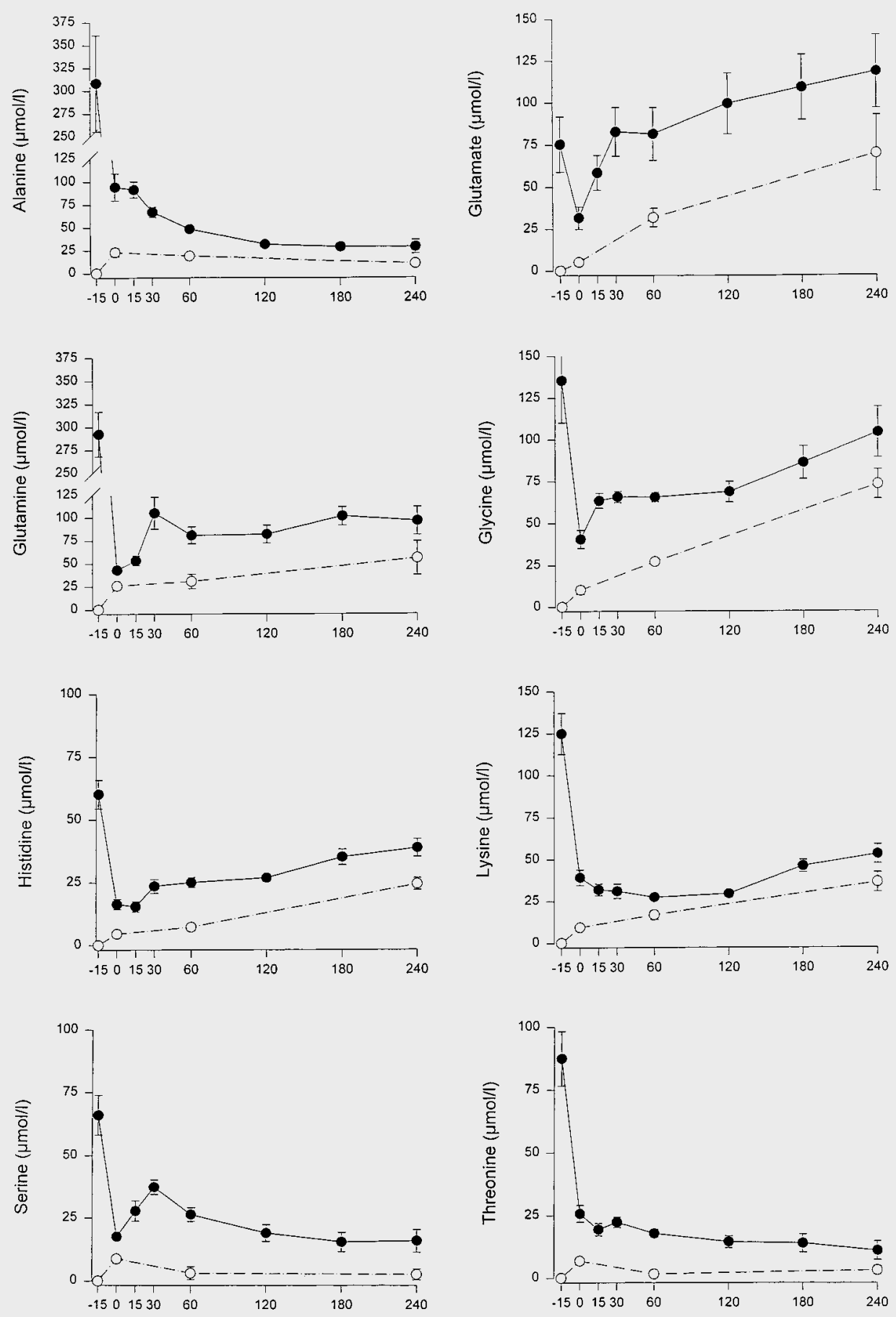
Fig. 5. The ratios of valine+leucine + isoleucine / tyrosine + phenylalanine concentrations were calculated on the basis of their perfusate concentration $(\mu \mathrm{mol} / \mathrm{l})$ at 0,60 , and 240 min. In FHF, the ratio seen clinically is close to 1 . The ratio increased from 3.8 before liver perfusion (i.e. $0 \mathrm{~min}$ ) to 8.8 after $60 \mathrm{~min}$ and further increased to 12.1 after $240 \mathrm{~min}$ of perfusion. Both increases were statistically significant.

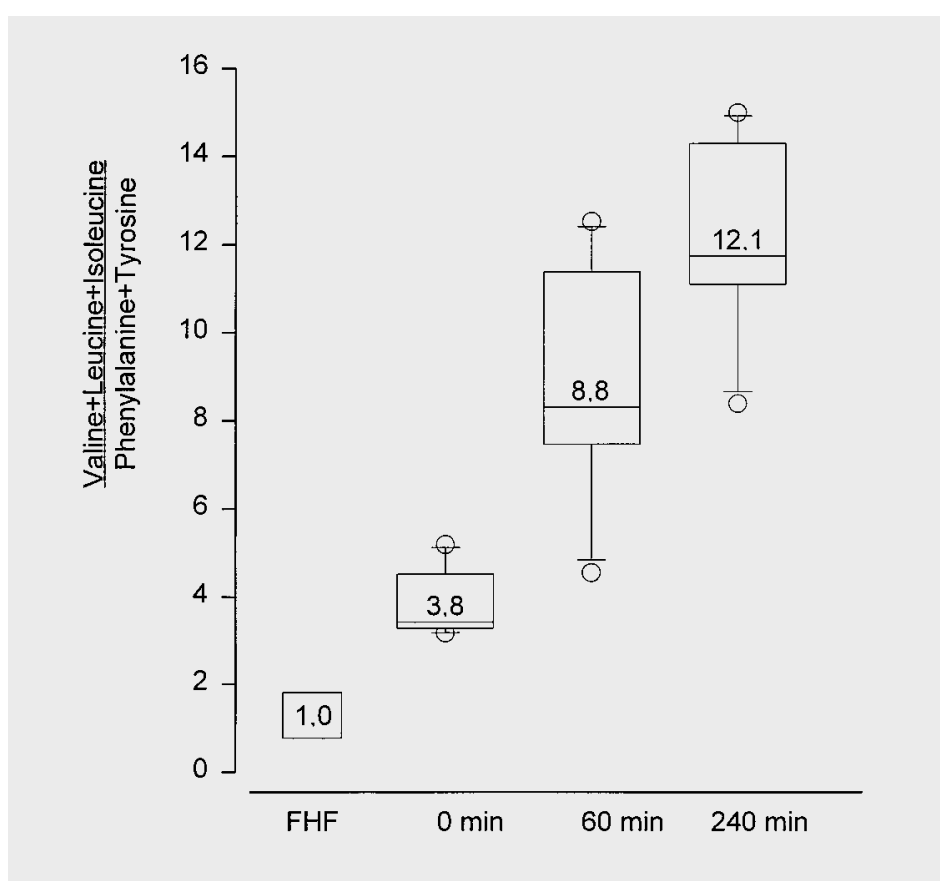

pensable for homogeneous peripheral perfusion particularly in the portal venous system [29]. Recently, we have shown that NELP can be further improved by simultaneous dialysis of the perfusate [14].

On the basis of physiological amounts of bile produced $(11.9 \mathrm{ml} / 100 \mathrm{~g} / 4 \mathrm{~h})$, very low activities of AST, ALT, and LDH (fig. 2), and the lack of gross or histologic evidence of poorly perfused areas, it is our opinion that this system provides excellent physiologic perfusion conditions.

Since PAA metabolism depends on the functional integrity of the liver, the results of a

Fig. 4. The concentrations of alanine, glutamate, glutamine, glycine, histidine, lysine, serine, and threonine in the perfusate and dialysate are shown. Perfusion conditions and parameters were identical to those in figure 3 .

Xenogeneic, Extracorporeal Liver Perfusion Improves Fischer's Ratio carefully perfused extracorporeal liver should be similar to those found under clinical conditions. We therefore analyzed changes in PAA concentrations within the perfusate. The design of our perfusion system consists of two closed circuits, one of 1.2 liters for the perfusate and one of 10 liters for the dialysate. Due to the circuit design of our perfusion, all concentrations of PAA within the perfusate decrease from the moment the dialyzer was connected to the perfusion system. This is the result of a dilution phenomenon since PAA cross the membrane of the dialyzer. Therefore, concentrations of PAA in the dialysate were included in the calculation for uptake or production of amino acids.

Once equilibration of the perfusion and dialysis circuit was established, reperfusion of the liver was started at time point $0 \mathrm{~min}$. Following reperfusion, changes in PAA concentrations in the perfusate or dialysate could

Eur Surg Res 1999;31:230-239 237 
only be attributed to their release or utilization by the liver.

The concentration of all BCAA - valine, leucine and isoleucine - increased significantly in the perfusate as well as in the dialysate during the 4-hour perfusion. The AAA phenylalanine increased slightly to plasma concentrations noted before perfusion while the other AAA tyrosine decreased during perfusion. As a result, the BCAA/AAA ratio increased from 3.8 to $8.8(\mathrm{p}<0.01)$ after $60 \mathrm{~min}$ and to 12.1 after $240 \mathrm{~min}$ of perfusion ( $<<$ 0.001 ). The increase from 3.8 (normal ratio) towards artificially high ratios of 8.8 and 12.1 should provide a HE patient with some benefit since the patient's pathologically low ratio of around 1 would increase substantially. This view is further supported by a similarly increased ratio in the 10 liters of dialysate.

Although perfusate concentrations of threonine, alanine and tyrosine were initially low, these dropped further during perfusion. Serine was released after reperfusion and then taken up by the liver, which may be due to a gluconeogenic effect because the rate of glucose synthesis from alanine and serine is far higher than that observed for all other PAA during liver perfusion [30]. While this might not play an important role in the elevated PAA levels during FHF, threonine, serine, alanine and tyrosine are likely to be metabolized in larger quantities if the extracorporeal liver perfusion is performed as an isolated perfusion over a longer period of time, i.e. for preservation or pharmacological studies. We would suggest to substitute for their loss either by addition to the perfusate or to the dialysate. This suggestion is further based on an observation during normothermic liver perfusion of ischemia-damaged livers in which addition of amino acids was of particular importance for liver resuscitation [31].

The concentration of glycine, histidine, lysine, glutamine, and glutamate increased in the perfusate as well as in the dialysate. We cannot conclude with certainty that the extracorporeally perfused liver would release these PAA when perfused with high concentrations of PAA, e.g. in patients with FHF, but it seems rather unlikely that it will metabolize large quantities of these amino acids [32].

More than 600 enzymatic systems are known currently causing many metabolic changes in case of liver failure [33]. More like$1 y, H E$ is of a multifactorial origin. In this context, the importance of the amino acid pattern in the pathogenesis of HE becomes more and more evident [26, 34].

For the first time we could show that an improved NELP system significantly raises the BCAA/AAA ratio. This system therefore may improve the encephalopathic state of FHF patients waiting for liver transplantation.

\section{References}

1 Ferenci P: Pathophysiology of hepatic encephalopathy. Hepatogastroenterology 1991;38:371-376.

2 O'Grady JG, Alexander GJ, Hayllar KM, Williams R: Early indicators of prognosis in fulminant hepatic failure. Gastroenterology 1989;97:439_ 445.
3 Ringe B, Pichlmayr R, Lauchart W, Müller R: Indications and results of liver transplantation in acute hepatic failure. Transplant Proc 1986;18: 86-88.

4 Bismuth H, Samuel D, Gugenheim J, Castaing D, Bernuau J, Rueff B, Benhamou JP: Emergency liver transplantation for fulminant hepatitis. Ann Intern Med 1987;107: 337-341.
5 Starzl TE, Demetris AJ, van Thiel DH: Liver transplantation (1). N Engl J Med 1989;321:1014-1022.

6 Matsubara S: Combination of plasma exchange and continuous hemofiltration as temporary metabolic support for patients with acute liver failure. Artif Organs 1994;18:363366. 
7 Fischer JE, Funovics JM, Aguirre A, James JH, Keane JM, Wesdorp R, Yoshimura N, Westman T: The role of plasma amino acids in hepatic encephalopathy. Surgery 1975;78: 276-290.

8 James JH, Ziparo V, Jeppsson B, Fischer JE: Hyperammonaemia, plasma aminoacid imbalance, and blood-brain aminoacid transport: A unified theory of portal-systemic encephalopathy. Lancet 1979;ii:772775 .

9 Butterworth RF: Neuroactive amino acids in hepatic encephalopathy. Metab Brain Dis 1996;11:165-173.

10 Fischer JE, Rosen HM, Ebeid AM, James JH, Keane JM, Soeters PB: The effect of normalization of plasma amino acids on hepatic encephalopathy in man. Surgery 1976;80: 77-91.

11 Abouna GM, Fisher LM, Porter KA, Andres G: Experience in the treatment of hepatic failure by interemittent liver hemoperfusions. Surg Gynecol Obstet 1973;137:741-752.

12 Tung LC, Häring R, Waldschmidt J, Weber D: Erfahrungen mit der extrakorporalen Leberperfusion bei akutem Leberversagen. Zentralbl Chir 1980;105:1195-1205.

13 Chari RS, Collins BH, Magee JC, DiMaio JM, Kirk AD, Harland RC, McCann RL, Platt JL, Meyers WC: Brief report: Treatment of hepatic failure with ex vivo pig-liver perfusion followed by liver transplantation. N Engl J Med 1994;331:234 237.

14 Schön MR, Puhl G, Frank J, Neuhaus P: Hemodialysis improves results of pig liver perfusion after warm ischemic injury. Transplant Proc 1993;25:3239-3243.

15 Schön MR, Lemmens HP, Neuhaus P, Baehr P, Heil W, Pöhlein C, Thiery J, Hammer C: Improved xenogeneic extracorporeal liver perfusion. Transplant Proc 1994;26: 1293-1297.

16 Lee WM: Acute liver failure. N Engl J Med 1993;329:1862-1872.
17 Williams R, Wendon J: Indications for orthotopic liver transplantation in fulminant liver failure. Hepatology $1994 ; 20: 5-10$.

18 Iber FL, Rosen H, Levenson SM, Chalmers TC: The plasma amino acids in patients with liver failure. Nutrition 1993;9:569-578.

19 Record CO, Buxton B, Chase RA, Curzon G, Murray Lyon IM, Williams R: Plasma and brain amino acids in fulminant hepatic failure and their relationship to hepatic encephalopathy. Eur J Clin Invest 1976;6:387-394.

20 Chase RA, Davies M, Trewby PN, Silk DB, Williams R: Plasma amino acid profiles in patients with fulminant hepatic failure treated by repeated polyacrylonitrile membrane hemodialysis. Gastroenterology 1978;75:1033-1040.

21 Reilly J, Mehta R, Teperman L, Cemaj S, Tzakis A, Yanaga K, Ritter P, Rezak A, Makowka L: Nutritional support after liver transplantation: A randomized prospective study. $\mathbf{J}$ Parenter Enteral Nutr 1990;14:386391.

22 Vilstrup H, Gluud C, Hardt F, Kristensen M, Kohler O, Melgaard B, Dejgaard A, Hansen BA, Krintel JJ, Schutten $\mathrm{HJ}$, et al: Branched chain enriched amino acid versus glucose treatment of hepatic encephalopathy. A double-blind study of 65 patients with cirrhosis. J Hepatol 1990;10:291-296.

23 Gluud C: Branched-chain amino acids for hepatic encephalopathy? Hepatology 1991;13:812-813.

24 Plauth M, Egberts EH, Hamster W, Torok M, Müller $\mathrm{PH}$, Brand $\mathrm{O}$, Furst P, Dolle W: Long-term treatment of latent portosystemic encephalopathy with branched-chain amino acids. A double-blind placebo-controlled crossover study. J Hepatol 1993;17:308-314.

25 Grungreiff K, Kleine FD, Musil HE, Diete U, Franke D, Klauck S, Page I, Kleine S, Lossner B, Pfeiffer KP: Valin and verzweigtkettige Aminosäuren in der Behandlung der hepatischen Enzephalopathie. Z Gastroenterol 1993;31:235-241.
26 Chalasani N, Gitlin N: Severe recurrent hepatic encephalopathy that responded to oral branched chain amino acids. Am J Gastroenterol 1996; 91:1266-1268.

27 Naylor CD, O'Rourke K, Detsky AS, Baker JP: Parenteral nutrition with branched-chain amino acids in hepatic encephalopathy. A metaanalysis. Gastroenterology 1989;97: 1033-1042.

28 Fabrri A, Magrini N, Bianchi G, Zoli M, Marchesini G: Overview of randomized clinical trials of oral branched-chain amino acid treatment in chronic hepatic encephalopathy. J Parenter Enteral Nutr 1996; 20:159-164.

29 Neuhaus P, Blumhardt G: Extracorporeal liver perfusion: Applications of an improved model for experimental studies of the liver. Int $\mathbf{J}$ Artif Organs 1993;16:729-739.

30 Felig P: Amino acid metabolism in man. Annu Rev Biochem 1975;44: 933-955.

31 Schön MR, Hunt CJ, Pegg DE, Wight DG: The possibility of resuscitating livers after warm ischemic injury. Transplantation 1993;56: 24-31.

32 Roth E, Mühlbacher F, Rauhs R, Huk I, Soderland K, Funovics J: Free amino acids in plasma and muscle in fulminant hepatic coma during an extracorporeal liver perfusion. J Parenter Enteral Nutr 1982; 6:240-244.

33 Fischer JE: Branched-chain-enriched amino acid solutions in patients with liver failure: An early example of nutritional pharmacology. J Parenter Enteral Nutr 1990;14: 249S-256S.

34 Miwa Y, Kato M, Moriwaki H, Okuno M, Sugihara J, Ohnishi H, Yoshida T, Muto Y, Nakayama M, Morioka Y, et al: Effects of branched-chain amino acid infusion in protein metabolism in rats with acute hepatic failure. Hepatology 1995;22:291-296. 